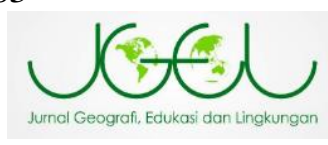

\title{
Evaluasi Pengembangan Tata Ruang Wilayah Terhadap Bencana Tanah Longsor di Kecamatan Cisarua, Kabupaten Bogor
}

\author{
Aditya Ramadhan', Dan Muhamad Kurniawan' \\ ${ }^{1}$ Departemen Geografi, Fakultas Matematika dan Ilmu Pengetahuan Alam, Universitas \\ Indonesia, Depok, Jawa Barat, Indonesia. \\ ${ }^{2}$ Staf Pengajar Teknik Geomatika SMKN 4 Tangerang, Kota Tangerang, Banten, \\ Indonesia
}

*E-mail: aditya.ramadhan01@ui.ac.id

Received: 01062021 / Accepted: 3006 2021/ Published online: 27072021

\begin{abstract}
ABSTRAK
Pengembangan wilayah yang terjadi di suatu daerah sejatinya harus sesuai dengan perencanaan tata ruang agar tejadinya sinergi antara kelestarian, rasa aman, dan kesejahteraan dalam kualitas hidup penduduknya. Kecamatan Cisarua termasuk wilayah di sisi selatan Kabupaten Bogor serta berbatasan dengan Kabupaten Cianjur yang memilki topografi dataran tinggi sehingga diasumsikan dengan zona rawan bencana tanah longsor. Penelitian ini bertujuan untuk membuat peta kerawanan tanah longsor berdasarkan tiga klasifikasi yaitu rendah, sedang, dan tinggi serta mengevaluasi perencaan pola ruang khususnya area permukiman terhadap peta kerawanan tanah longsor tersebut. Metode yang digunakan dalam penelitian ini adalah skoring dan pembobotan. Selanjutnya, dilakukan teknik tumpang susun (overlay) dengan memanfaatkan teknologi sistem informasi geografi menggunakan lima variabel fisik yaitu kondisi geologi, kemiringan lereng, curah hujan, penggunaan lahan, dan jenis tanah. Berdasarkan temuan penelitian yang telah dilakukan, Kecamatan Cisarua memiliki zona kerawanan rendah seluas $20,84 \mathrm{Km}^{2}$ atau sebesar (31,24\%), zona kerawanan sedang seluas $32,21 \mathrm{Km}^{2}$ atau sebesar (48,28\%), dan zona kerawanan tinggi seluas $13,66 \mathrm{Km}^{2}$ atau sebesar $(20,48 \%)$. Pada evaluasi pola ruang terhadap zona rawan tanah longsor, tidak terdapat zona kerawanan tinggi dalam deliniasi kawasan permukiman. Kesimpulannya, rencana pola ruang khususnya permukiman yang telah dibuat dan ditetapkan oleh pemerintah sudah tepat untuk pengembangan wilayah di Kecamatan Cisarua.
\end{abstract}

Kata Kunci: Evaluasi Pengembangan Wilayah, Tata Ruang, Bencana Tanah Longsor

\section{ABSTRACT}

Regional development that occurs in an area must actually be in accordance with spatial planning so that there is a synergy between sustainability, security, and welfare in the quality of life of its inhabitants. Cisarua District is an area on the south side of Bogor Regency and is bordered by Cianjur Regency which has a highland topography so that it is assumed to be a landslide prone zone. This study aims to create a landslide susceptibility map based on three classifications, namely low, medium, and high and evaluate the spatial pattern planning, especially residential areas, against the landslide hazard map. The method used in this research is scoring and weighting. Furthermore, 
an overlay technique is carried out by utilizing geographic information system technology using five physical variables, namely geological conditions, slope, rainfall, land use, and soil types. Based on the findings of the research that has been done, Cisarua District has a low vulnerability zone of $20.84 \mathrm{Km}^{2}$ or (31.24\%), a moderate vulnerability zone of $32.21 \mathrm{Km}^{2}$ or (48.28\%), and a high vulnerability zone of 13. .66 $\mathrm{Km}^{2}$ or equal to (20.48\%). In the evaluation of the spatial pattern of the landslide-prone zone, there is no high-risk zone in the delineation of the residential area. In conclusion, the spatial pattern plan, especially settlements that have been made and determined by the government is appropriate for regional development in Cisarua District.

Key Words: Evaluation of Regional Development, Spatial Planning, Landslide Disaster

\section{PENDAHULUAN}

Kabupaten Bogor merupakan daerah yang rawan dengan potensi bencana, daerah ini sering terjadi bencana tanah longsor yang disebabkan dari pengaruh faktor hidrometeorologi (Permadi et al., 2018). Dalam Indeks Risiko Bencana Indonesia tahun 2013, disebutkan risiko daerah ini terhadap bencana tanah longsor berstatus tinggi (BNPB, 2013). Upaya kajian dan kontribusi penelitian diperlukan untuk memperkuat informasi dan inventarisasi bahaya longsor di daerah ini khususnya pada area yang lebih sempit seperti tingkat Kecamatan agar informasi kerawanan menjadi lebih detail, seiring meningkatknya kebutuhan akan lahan dalam rangka pertumbuhan penduduk dan pengembangan wilayah yang semakin meluas. Fenomena ini terjadi seiring berjalannya waktu dan meningkatnya populasi yang mendorong maraknya pembangunan di Kabupaten Bogor (Kusrini et al., 2016).

Faktor lainnya yang mempengaruhi fenomena tersebut adalah letak geografis Kabupaten Bogor diketahui sebagai salah satu Kawasan Strategis Nasional Jabodetabekpunjur. Secara otomatis daerah ini mengalami pengembangan wilayah untuk mendorong terciptanya pertumbuhan ekonomi serta aksesibilitas yang mudah. Seperti contohnya, kawasan Puncak biasanya ramai karena menjadi alternatif pariwisata penduduk kota Jakarta karena lokasinya yang dekat dengan Ibukota tersebut (Trimarwanti, 2014). Terfokus kepada Kecamatan Cisarua sebagai area studi, daerah ini dikenal sebagai dataran tinggi pada kawasan Puncak Bogor dikarenakan letaknya paling atas dan sebagian wilayahnya merupakan gugusan perbukitan dari Taman Nasional Gunung Gede Pangrango (Rahman, 2011). Didasari hal tersebut, perencanaan tata ruang berdasarkan kerawanan bencana tanah longsor sangat penting mengingat kecamatan ini berada di dataran tinggi. Topografi yang didominasi dengan kemiringan lereng curam menggambarkan secara sederhana bahwa wilayah tersebut rawan terjadinya pergerakan tanah yang menyebabkan bencana alam seperti tanah longsor (Yassar et al., 2020).

Fenomena ini menuntut bahwa pengembangan pembangunan khususnya kawasan hunian harus dibatasi dan dilakukan pada wilayah yang aman dari bahaya tanah longsor. Berdasarkan Rencana Strategis dalam RTRW 20162036 Kabupaten Bogor, disebutkan bahwa perencanaan tersebut bertujuan untuk pemanfaatan ruang yang berdasarakan lingkungan yang berkelanjutan serta merendahkan rasio tutupan lahan artifisial terhadap kawasan konservasi yang sejalan dengan 
pembangunan infrastruktur terhadap pengembangan wilayah dan ekonomi.

Peningkatan akan pembangunan dan pemanfaatan lahan akibat pertumbuhan penduduk tentunya dapat mempengaruhi kelestarian fungsi kawasan sebagai kawasan konservasi yang sebenarnya harus dilindungi, maka dari itu pembuatan perencanaan tata ruang merupakan solusi awal yang tepat (Rachmawati et al., 2013) Penelitian ini bertujuan melihat apakah terjadi penyimpangan terhadap rencana tata ruang terhadap kawasan rawan tanah longsor yang ada di Kecamatan Cisarua, kondisi tersebut bisa saja terjadi karena regulasi yang tidak konsisten dalam mewujudkan tata ruang yang telah direncanakan atau variabel rawan bencana belum menjadi acuan dalam merencanakan tata ruang wilayah, padahal bencana memiliki dampak yang besar dan masif dalam kesejahteraan manusia khususnya yang tinggal di daerah tersebut (Fahmi et al., 2016).

Substansi dari hasil peta berkaitan dengan kerawanan bencana sebagian besar terfokus kepada inventarisasi zona. Dalam pembuatan peta kerawanan dilakukan penyempitan analisis pada variabel faktor pendorong serta dampak bencana tersebut terhadap kewilayahan seperti dalam (Dewi et al., 2017). Penelitian tentang pembuatan peta zonasi wilayah tanah longsor memang hampir seluruhnya menggunakan variabel variabel alami dengan ketetapan berasaskan literatur terkait dan dilakukan dengan teknik tumpang susun dalam software SIG (Susanti et al., 2017). Sedangkan, penelitian terbaru yang dilakukan saat ini berusaha mencari jawaban atas perencanaan kebijakan spasial dibuat dengan mengedepankan keamanan terhadap bahaya tanah longsor ditinjau dari luasan deliniasi terutama pada Kawasan permukiman. Kawasan ini diketahui memiliki akivitas kehidupan lebih intens dibandingkan wilayah non pemukiman seperti hutan, sawah dan perkebunan. Evaluasi dilakukan pada kondisi eksisting terhadap perencanaan tata ruang yang dikomparasi dengan zona kerawanan tanah longsor.

Berdasarkan peneltian yang relevan, dinyatakan bahwa efek bencana paling terasa secara signifikan adalah dampak terhadap kehidupan manusia. Dalam pendekatan keruangan, kehidupan terjadi umumnya pada kawasan permukiman. Maka dari itu, apakah perencanaan permukiman yang telah ditetakan pada Kecamatan Cisarua telah aman dari bahaya longsor.

\section{METODE PENELITIAN Lokasi Penelitian}

Penelitian ini meliputi wilayah Kecamatan Cisarua, Kabupaten Bogor, Provinsi Jawa Barat dengan letak absolut pada $06^{\circ} 55^{\prime} 48,08^{\prime \prime}$ BT dan $6^{\circ} 40^{\prime} 40,32^{\prime \prime}$ LS dengan total luas wilayah seluas 66,72 $\mathrm{Km}^{2}$ dengan 10 Desa. Pada daerah ini penggunaan lahan yang terbentuk seperti pemukiman berada pada kelerengan landai - agak curam dan dilalui jalan raya Puncak yang pada setiap sisinya didominasi jurang dan tebing punggungan bukit yang dikhawatirkan sewaktu waktu bisa terjadi longsor. Untuk gambaran lokasi area studi dapat dilihat pada (Gambar 1) dan desa desa yang terdapat di Kecamatan Cisarua beserta luasnya bisa dilihat pada (Tabel 1).

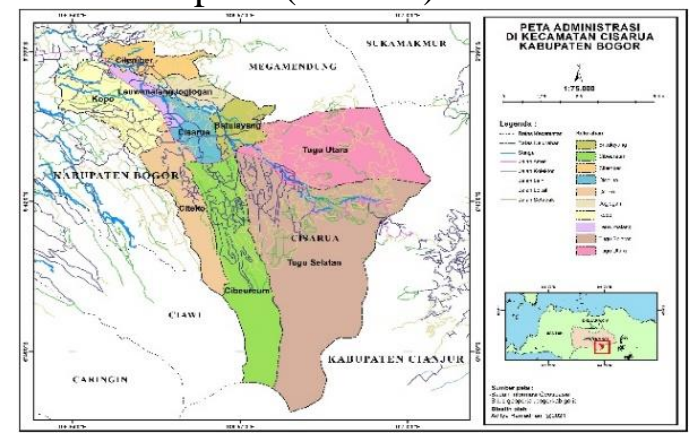

Gambar 1. Peta Administrasi Kecamatan Cisarua 
Tabel 1. Desa Berdasarkan Luas di Kecamatan Cisarua

\begin{tabular}{cccc}
\hline No & Desa & $\begin{array}{c}\text { Luas } \\
(\mathbf{K m 2})\end{array}$ & $\begin{array}{c}\text { Persentase } \\
(\mathbf{\%})\end{array}$ \\
\hline 1. & Batu Layang & 2,26 & 3,39 \\
\hline $\mathbf{2 .}$ & Cibereum & 11,29 & 16,92 \\
\hline 3. & Cilember & 2 & 3 \\
\hline $\mathbf{4 .}$ & Cisarua & 2 & 3 \\
\hline $\mathbf{5 .}$ & Citeko & 4,61 & 6,91 \\
\hline $\mathbf{6 .}$ & Jogjogan & 4,54 & 6,8 \\
\hline $\mathbf{7 .}$ & Kopo & 4,53 & 6,79 \\
\hline $\mathbf{8 .}$ & Leuwimalang & 1,35 & 2,02 \\
\hline $\mathbf{9 .}$ & Tugu Selatan & 17,12 & 25,66 \\
\hline $\mathbf{1 0}$ & Tugu Utara & 17,02 & 25,51 \\
\hline & Total & 66,72 & 100 \\
\hline
\end{tabular}

Sumber: (Badan Pusat Statistik Kabupaten Bogor, 2019).

\section{Jenis Dan Metode Penelitian}

Jenis penelitian dalam topik ini merupakan penelitian kuantitatif dengan memanfaatkan teknologi sistem informasi geografis. Metode dalam penelitian ini adalah penelitian deskriptif dengan menggunakan teknik pemberian skor dan pembobotan yang akan dilakukan analisis tumpang tindih (overlay) terhadap variabel yang digunakan. Penggunaan fitur intersect dalam software Arcmap GIS 10.3 berguna untuk menggabungkan atribut spasial terhadap variabel yang digunakan. Setelah langkah tersebut dilakukan maka akan didapatkan hasil berupa peta rawan longsor di Kecamatan Cisarua. Selanjutnya, dilakukan proses evaluasi terhadap Rencana Tata Ruang Wilayah (RTRW) di Kabupaten Bogor.

\section{Metode Pengumpulan, Pengolahan, dan Analisis Data}

Data dalam penelitian ini adalah data langsung dari lapangan yang dibuat oleh instansi terkait (Tabel 2). Akan tetapi, peneliti mengaksesnya dari studi literatur dari lembaga pencatatan dan statistik, jurnal relevan dan situs resmi instansi terkait baik data tabular berupa tabel maupun data spasial untuk analisis menggunakan SIG. Maka dari itu, penggunaan data merupakan data sekunder yang diperlukan untuk memberi informasi lanjutan terhadap fenomena yang akan diteliti selain data yang diperoleh langsung ke lapangan (Omukuti et al., 2021).

Tabel 2. Data Sekunder Yang Digunakan

\begin{tabular}{|c|c|c|c|}
\hline No & Data & Bentuk & $\begin{array}{c}\text { Sumber } \\
\text { Data }\end{array}$ \\
\hline 1. & $\begin{array}{lr}\text { Peta } & \text { Digital } \\
\text { Rupa } & \text { Bumi } \\
\text { Indonesia } & \end{array}$ & Vektor & $\begin{array}{l}\text { Badan } \\
\text { Informasi } \\
\text { Geospasial } \\
\text { (BIG) }\end{array}$ \\
\hline 2. & $\begin{array}{l}\text { Curah Hujan } \\
\text { 2020 Jawa Barat }\end{array}$ & Raster & $\begin{array}{l}\text { https://gis.b } \\
\text { mkg.go.id/a } \\
\text { rcgis/home/ }\end{array}$ \\
\hline 3. & $\begin{array}{l}\text { Kemiringan } \\
\text { Lereng }\end{array}$ & Vektor & $\begin{array}{l}\text { https://www } \\
\text {.indonesia- } \\
\text { geospasial.c } \\
\text { om/ }\end{array}$ \\
\hline 4. & $\begin{array}{l}\text { Kondisi Geologi } \\
\text { Jawa Barat }\end{array}$ & Vektor & $\begin{array}{l}\text { https://www } \\
\text {.indonesia- } \\
\text { geospasial.c } \\
\text { om/ }\end{array}$ \\
\hline 5. & $\begin{array}{l}\text { Jenis Tanah } \\
\text { Kabupaten } \\
\text { Bogor }\end{array}$ & Vektor & $\begin{array}{l}\text { Balai Besar } \\
\text { Litbang } \\
\text { Sumber } \\
\text { Daya Lahan } \\
\text { Pertanian } \\
\text { (BBSDLP) }\end{array}$ \\
\hline 6. & $\begin{array}{l}\text { Penggunaan } \\
\text { Lahan } \\
\text { Kecamatan } \\
\text { Cisarua }\end{array}$ & Vektor & $\begin{array}{l}\text { https://www } \\
\text {.indonesia- } \\
\text { geospasial.c } \\
\text { om/ }\end{array}$ \\
\hline 7. & $\begin{array}{l}\text { RTRW } \\
\text { Kabupaten } \\
\text { Bogor 2016- } \\
\text { 2036 Kabupaten } \\
\text { Bogor }\end{array}$ & Vektor & $\begin{array}{l}\text { https://geop } \\
\text { ortal.bogork } \\
\text { ab.go.id/ser } \\
\text { ver/services }\end{array}$ \\
\hline
\end{tabular}

Sumber: (Penulis, 2021)

Tabel 3. Variabel Yang Digunakan

\begin{tabular}{cclc}
\hline No & Data & Keterangan & Satuan \\
\hline 1. & Curah & Merupakan & \\
& Hujan & pengukuran & \\
& & jumlah air yang & \\
& jatuh ke & \\
& permukaan & \\
& tanah dari & $\mathrm{mm} /$ \\
& proses & tahun \\
& presipitasi & \\
& selama periode & \\
& tertentu, & \\
& digunakan & \\
& curah hujan & \\
& tahunan pada & \\
& &
\end{tabular}




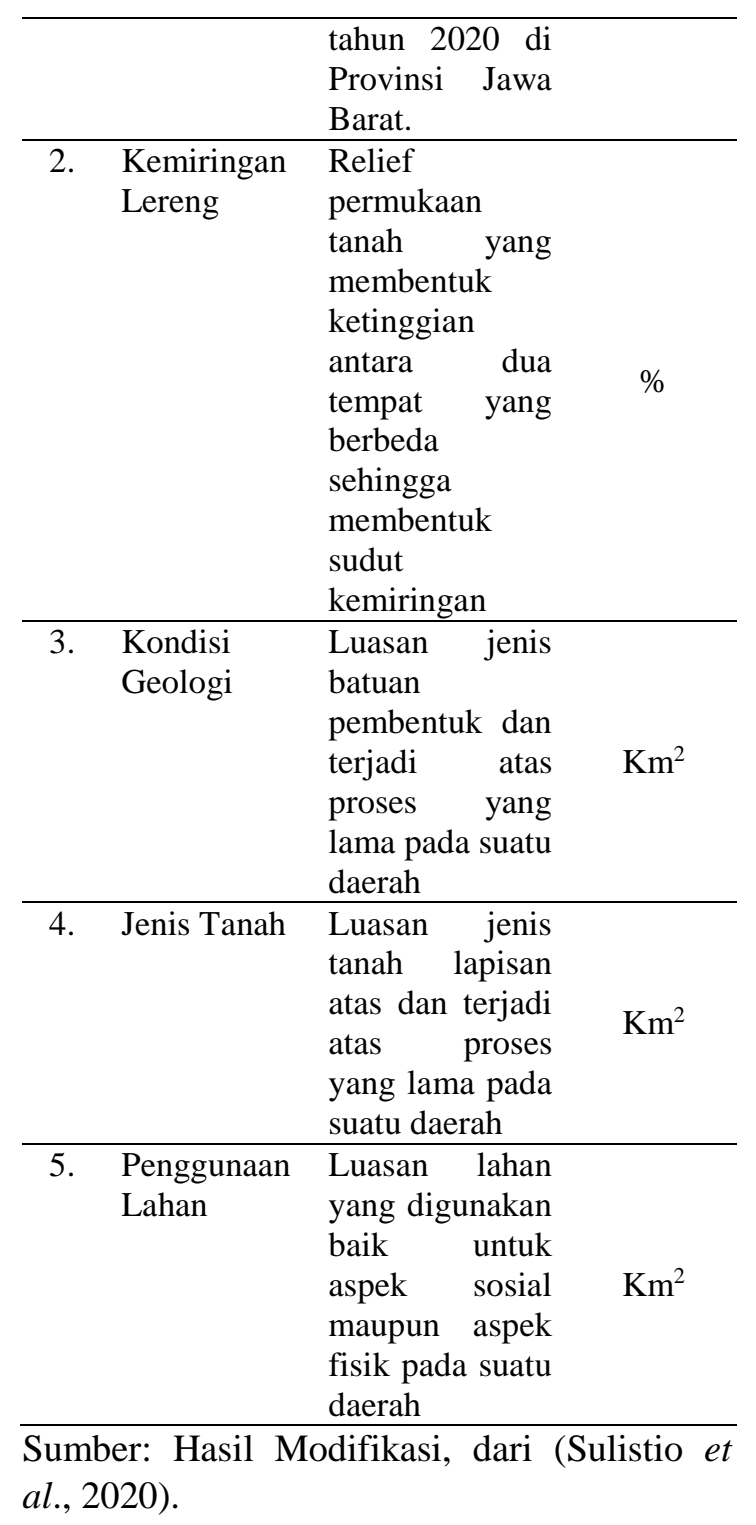

Dalam pembuatan peta kerawanan longsor di Kecamatan Cisarua Kabupaten Bogor diperlukan variabel serta skor dan pembobotan untuk mengetahui seberapa besar unsur yang digunakan berpengaruh terhadap hasil peta. Setiap skor dijumlahkan dan dikalikan dengan bobot yang telah ditentukan, hasil yang diperoleh akan diklasifkasikan menggunakan tiga tingkatan yakni, rendah, sedang, dan tinggi (Sihotang, 2016). Untuk Analisis data dilakukan pemberian skor dan pembobotan dengan klasifikasi pada Tabel 4, 5, 6,7 dan 8 . Untuk diagram alir pesnkoran dan pembobotan disajikan pada Gambar 2.

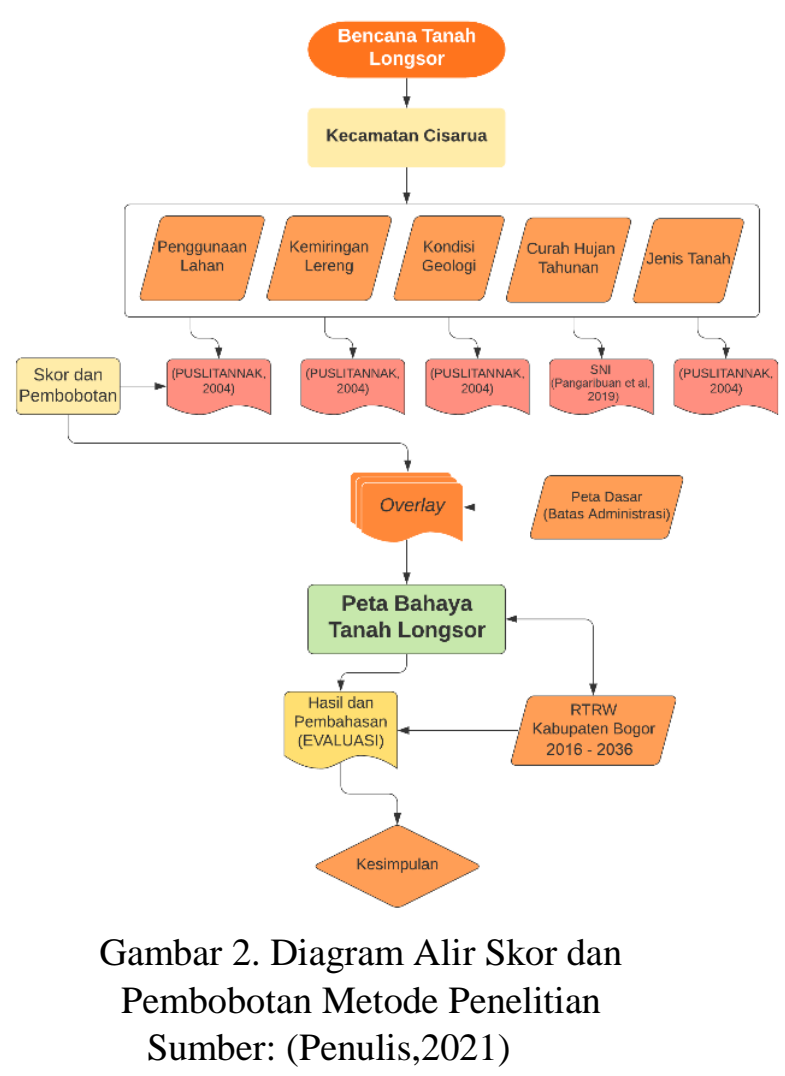

Tabel 4. Klasifikasi Skor dan Pembobotan Curah Hujan

\begin{tabular}{|c|c|c|c|}
\hline No & $\begin{array}{c}\text { Curah Hujan } \\
\text { (mm/tahun) }\end{array}$ & Skor & $\begin{array}{c}\text { Bobot } \\
(\%)\end{array}$ \\
\hline 1. & $<2000$ & 1 & \\
\hline 2. & $2000-3000$ & 2 & 30 \\
\hline 3. & $>3000$ & 3 & \\
\hline
\end{tabular}

Sumber: Hasil Modifikasi dari SNI; (Pangaribuan et al., 2019).

Tabel 5. Klasifikasi Skor dan Pembobotan Kemiringan Lereng

\begin{tabular}{|c|c|c|c|}
\hline No & $\begin{array}{c}\text { Kemiringan Lereng } \\
(\%)\end{array}$ & Skor & $\begin{array}{c}\text { Bobot } \\
(\%)\end{array}$ \\
\hline 1. & $0-8 \%$ & 1 & \multirow{5}{*}{20} \\
\hline 2. & $8-15 \%$ & 2 & \\
\hline 3. & $15-25 \%$ & 3 & \\
\hline 4. & $25-45 \%$ & 4 & \\
\hline 5. & $>45 \%$ & 5 & \\
\hline
\end{tabular}

Sumber: Hasil Modifikasi dari
PUSLITTANAK dalam (Hardianto et al., 2020). 
Tabel 6. Klasifikasi Skor dan Pembobotan Kondisi Geologi

\begin{tabular}{|c|c|c|c|}
\hline No & $\begin{array}{l}\text { Kondisi Geologi } \\
\text { (mm/tahun) }\end{array}$ & Skor & $\begin{array}{l}\text { Bobot } \\
(\%)\end{array}$ \\
\hline 1. & Aluvial (Qav,Qa ) & 1 & \multirow{5}{*}{20} \\
\hline 2. & $\begin{array}{c}\text { Vulkanik Primer } \\
\text { (Qvcp, Qvba, Qvk, } \\
\text { Qvl, Qvpo, Qvsl, } \\
\text { Qvu) }\end{array}$ & 2 & \\
\hline 3. & $\begin{array}{c}\text { Sedimen Primer (Tmi, } \\
\text { Tmn ) }\end{array}$ & 3 & \\
\hline 4. & $\begin{array}{l}\text { Vulkanik Sekunder } \\
\text { (Qvsb, Qvst, Qvb) }\end{array}$ & 4 & \\
\hline 5. & $\begin{array}{l}\text { Sedimen Sekunder } \\
\text { (Tmb, Tmbl, Tmtb) }\end{array}$ & 4 & \\
\hline $\begin{array}{l}\text { USLI } \\
\text { D20) }\end{array}$ & $\begin{array}{cc}\text { Hasil } & \text { Mo } \\
\text { ANAK dalam } & \end{array}$ & $\begin{array}{l}\text { fikasi } \\
\text { lianto }\end{array}$ & $\begin{array}{l}\text { dari } \\
\text { et } \quad \text { al., }\end{array}$ \\
\hline
\end{tabular}

Tabel 7. Klasifikasi Skor dan Pembobotan Jenis Tanah

\begin{tabular}{cccc}
\hline No & $\begin{array}{c}\text { Jenis Tanah } \\
(\mathbf{m m} / \text { tahun })\end{array}$ & Skor & $\begin{array}{c}\text { Bobot } \\
(\mathbf{\%})\end{array}$ \\
\cline { 1 - 3 } 1. & Aluvial & 1 & \\
\cline { 1 - 3 } 2. & $\begin{array}{c}\text { Asosiasi Latosol } \\
\text { Coklat Kekuningan }\end{array}$ & 2 & \multirow{2}{*}{10} \\
\cline { 1 - 2 } 3. & Latosol Coklat & 3 & \\
\cline { 1 - 3 } 4. & Andosol, Podsolik & 4 & \\
\cline { 1 - 3 } 5. & Regosol & 5 & \multirow{2}{*}{ Sari }
\end{tabular}
PUSLITTANAK dalam (Hardianto et al., 2020)

Tabel 8. Klasifikasi Skor dan Pembobotan Penggunaan Lahan

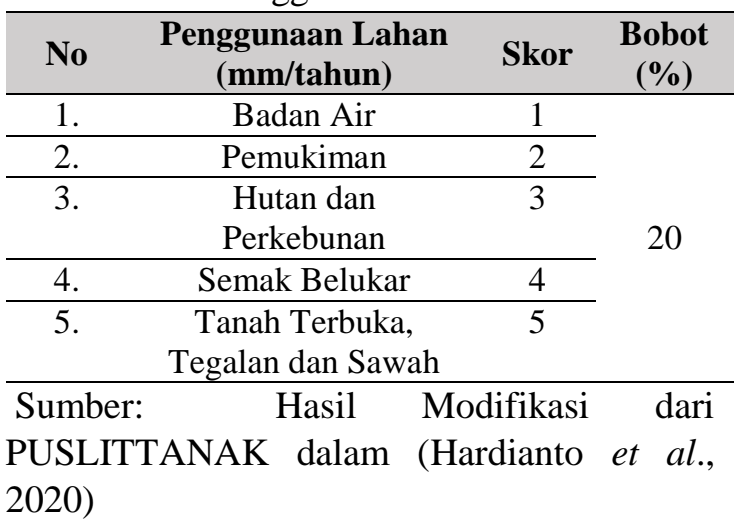

\section{HASIL DAN PEMBAHASAN Peta Variabel Kerawanan Longsor}

Dari peta curah hujan (Gambar 3), diketahui bahwa daerah tersebut memiliki dua wilayah curah hujan yaitu di sebagian kecil sisi timur sebesar $2500-3000$ $\mathrm{mm} /$ tahun dengan kategori sedang, dan sebagian besar didominasi curah hujan sebesar $>3000-3800 \mathrm{~mm} /$ tahun dengan kategori tinggi.

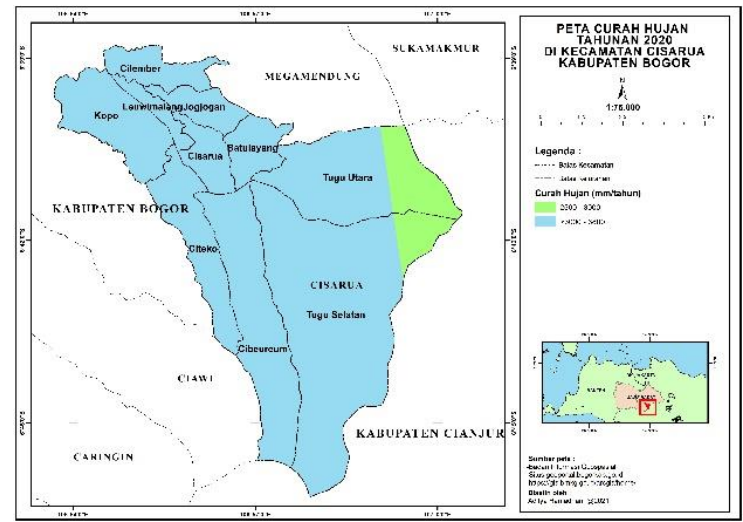

Gambar 3. Curah Hujan Tahunan Kecamatan Cisarua

Terdapat delapan jenis penggunaan lahan seperti kawasan hutan dengan luas 37,72 $\mathrm{Km}^{2} \quad(56,53 \%)$, kawasan pertanian seluas $8 \mathrm{Km}^{2}$ $(11,99 \%)$, Perkebunan dan tanah terbuka seluas $9 \mathrm{Km}^{2}$ (13,49\%), dan Kawasan Permukiman seluas $12 \mathrm{Km}^{2}(17,99 \%)$ (Gambar 4). Diketahui pada wilayah ini kawasan hutan masih mendominasi sebagai penggunaan lahan terluas.

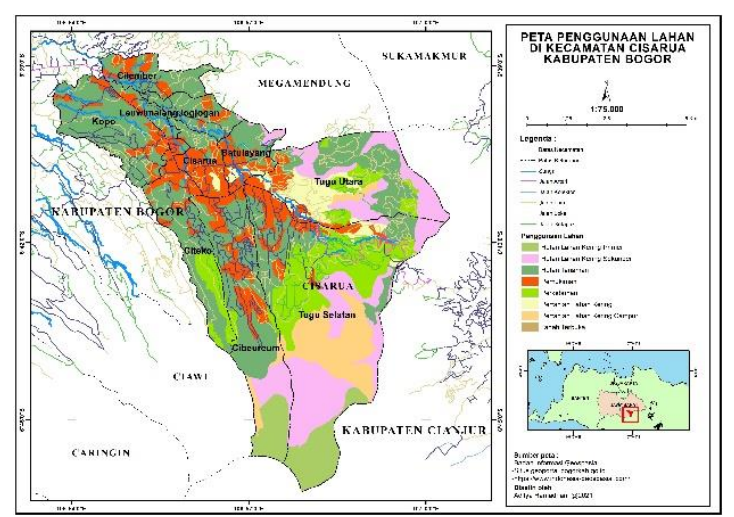

Gambar 4. Penggunaan Lahan Kecamatan Cisarua 


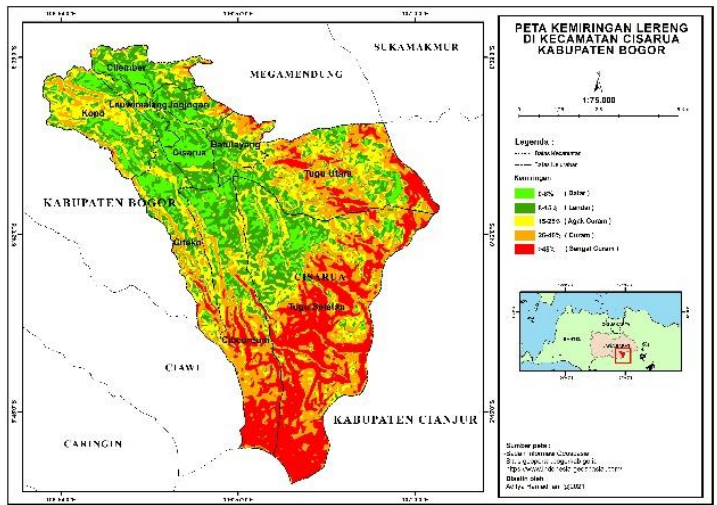

Gambar 5. Kemiringan Lereng Kecamatan Cisarua

Untuk kemiringan lereng memiliki kategori yang bervariasi mulai dari bentuk Datar seluas $10,20 \mathrm{Km}^{2}(15,29 \%)$, Landai seluas $11,36 \mathrm{Km}^{2}(17,03 \%)$, Agak curam seluas $9,80 \mathrm{Km}^{2}(14,69 \%)$, Curam seluas $17 \mathrm{Km}^{2}(25,48 \%)$, dan yang paling tinggi adalah kategori Sangat curam dengan luas $18,36 \mathrm{Km}^{2}(27,52 \%)$ (Gambar 5).

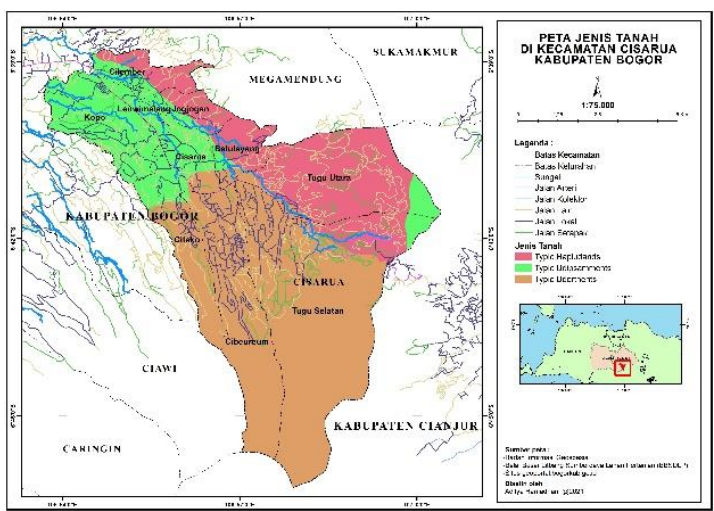

Gambar 6. Jenis Tanah Kecamatan Cisarua

Wilayah ini terdiri dari tiga jenis tanah yaitu Typic Hapludants seluas 16,86 $\mathrm{Km}^{2}$ (25,27\%), Typic Udipsament seluas $13,5 \mathrm{Km}^{2}$ dan Typic Udorthents seluas $36,36 \mathrm{Km}^{2}(54,5 \%)$ (Gambar 6).

Berdasarkan peta kondisi geologi, wilayah ini tersusun atas batuan vulkanik primer yakni $Q v b a$ seluas $8,88 \mathrm{Km}^{2}$ (13,31\%), $Q v k$ seluas $19,28 \mathrm{Km}^{2}(28,9 \%)$, Qvpo seluas $38,56 \mathrm{Km}^{2} \quad(57,79 \%)$. Struktur geologi disini terbentuk dari aliran lava dan enadapan gunung api tua (Gambar 7).

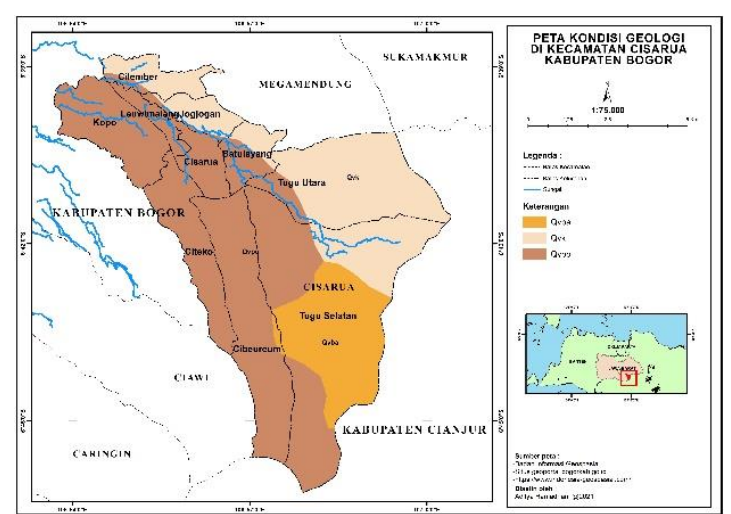

Gambar 7. Kondisi Geologi Kecamatan Cisarua

\section{Peta Kerawanan Longsor Kecamatan Cisarua}

Setelah dilakukan proses overlay terhadap variabel kerawanan tanah longsor yang menghasilkan tiga klasifikasi dengan mencari selisih terhadap nilai tertinggi ke nilai terendah dan dibagi tiga sesuai kelas yang diingikan yaitu rendah, sedang dan tinggi.

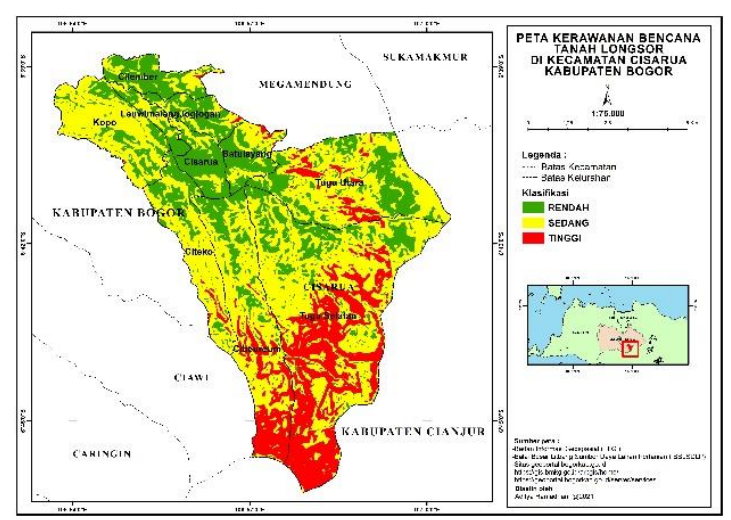

Gambar 8. Peta Kerawanan Bencana Tanah Longsor Kecamatan Cisarua

Berdasakan (Gambar 8) didapatkan hasil dari klasifikasi kerawanan longsor kelas rendah dengan warna hijau seluas $20,84 \mathrm{Km}^{2}(31,24 \%)$, untuk kelas sedang dengan warna kuning seluas $32,21 \mathrm{Km}^{2}$ (48,28\%), dan terakhir untuk kelas tinggi dengan warna merah seluas 13,66 $\mathrm{Km}^{2}$ (20,48\%). Digambarkan bahwa kerawanan longsor tinggi terjadi di sisi selatan Kecamatan Cisarua dengan dominasi kelerengan 25 - $>45 \%$ yaitu kelerengan curam hingga sangat curam. 
Daerah ini memang merupakan bagian dari punggungan Gunung Pangrango.

\section{Evaluasi Rencana Tata Ruang Wilayah Pemukiman Terhadap Kawasan Bencana Tanah Longsor Di Kecamatan Cisarua}

Didasari kepada tujuan penelitian, dilakukan evaluasi peta rencana pola ruang 2016 - 2036 Kecamatan Cisarua terhadap peta kerawanan bencana tanah longsor pada (Gambar 8). Pola ruang pemukiman di evaluasi karena memiliki dampak besar terhadap bencana tanah longsor seperti korban jiwa dan kerugian harta benda dibandingkan kawasan hutan, perkebunan, dan pertanian yang jarang terdapat aktivitas secara intensif. Bisa dilihat secara visual tidak ada tingkat kerawanan tinggi dengan warna merah yang terdapat pada deliniasi kawasan pemukiman, hanya ada klasifikasi rendah dan sedang dalam deliniasi tersebut.

Secara analisis luas, hanya 0,011 $\mathrm{Km}^{2}$ zona rawan longsor tinggi, untuk zona kerawanan sedang seluas $6,94 \mathrm{Km}^{2}$ dan zona kerawanan rendah seluas 8,94 $\mathrm{Km}^{2}$ (Gambar 10). Hal ini menujukkan bahwa pengembangan wilayah seperti contoh dalam rencana tata ruang, sudah dikategorikan aman dari bencana tanah longsor tingkat tinggi.

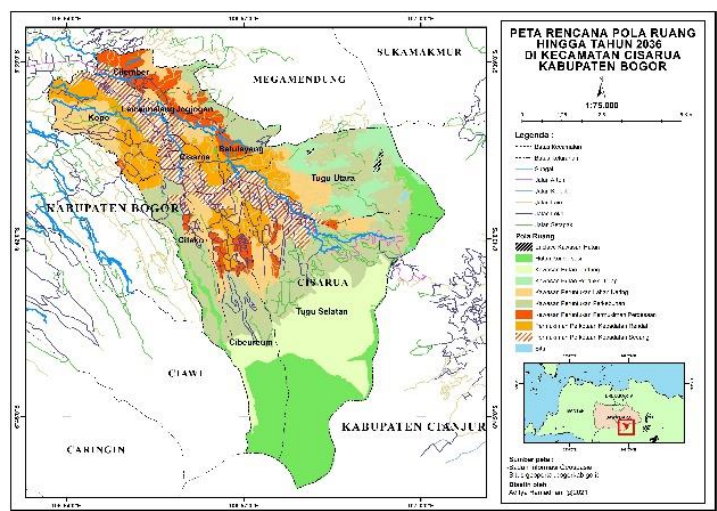

Gambar 9. Peta Rencana Pola Ruang 2016 2036 di Kecamatan Cisarua

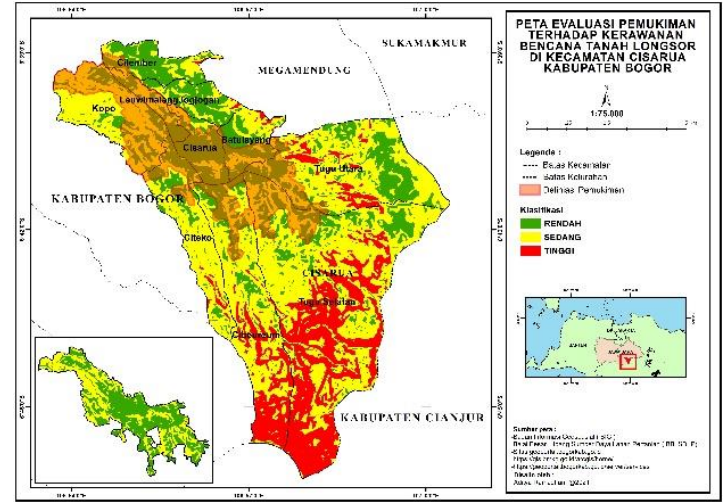

Gambar 10. Peta Evaluasi Pemukiman Terhadap Kerawanan Bencana Tanah Longsor Kecamatan Cisarua

Berdasarkan hasil yang telah diperoleh, didapatkan hasil zona kerawanan bahaya longsor. Klasifikasi longsor berguna untuk menunjukkan seberapa besar tingkat bahaya yang tejadi. Dalam skor dan pembobotan yang digunakan, secara persentase lebih besar pada variabel curah hujan. Hal ini mengindikasikan bahwa intensitas curah hujan memicu bencana longsor yang terjadi (Hasnawir, 2012). Curah hujan memiliki pengaruh terkait stabilitas lereng dan kondisi serapan tanah yang berhubungan dengan solidnya tanah akan pergeseran (Sarya et al., 2014).

Berkaitan dengan penggunaan skor dan bobot dalam penelitian ini menggunakan literatur dari kajian dan ketetapan dari instansi terkait maupun publikasi dari jurnal yang relevan. Namun pada penelitian lainnya ada yang menggunakan skor dan bobot dengan pengambilan data primer, dan digunakan metode seperti AHP. Metode ini merupakan analisis statistik yang populer karena dirasa paling representatif dalam segi temporal dan kondisi eksisting area studi dengan melibatkan keterangan dari para ahli seperti dalam (Mandal \& Mandal, 2018) dijelaskan bahwa untuk pengambilan keputusan dari pendekatan keruangan metode ini dapat meyederhanakan analisis masalah yang rumit. Menghadirkan perbandingan 
pasangan, dan sebagai alternatif untuk peneliti agar penelitian semakin detail.

Overlay merupakan teknik dalam sistem informasi geografis yang sebenarnya masuk ke metode pembuat keputusan berdasarkan multikriteria (MCDM). Teknik ini berguna dalam menggabungkan parameter penentu menjadi informasi pengambilan keputusan. Teknik ini dirasa tepat untuk mendeskripsikan data pengolahan menjadi peta dalam cakupan area yang luas. Kelebihannya, setiap poligon dari variabel memiliki nilai sampai ke unit terkecil, dan setiap unit tersebut memiliki pengaruh dari apa yang sudah digabungkan. Pada studi kasus bencana tanah longsor, overlay juga bisa digunakan untuk menggabungkan historis kejadian longsor sebelumnya sebagai informasi tambahan dalam penentuan zona rawan longsor dengan aritmatika seperti dalam (Kahal et al., 2021).

Kelemahan pada metode ini adalah klasifikasi yang digunakan belum bisa menjelaskan seberapa besaran dari tingkat bahaya longsor yang dipetakan, pada penelitian khususnya kajian klasifikasi tanah longsor secara mendalam, longsor sebaiknya dijabarkan dari jenis-jenis longsor, kedalaman longsor, arah gerakan longsoran, dan kecepatan longsoran (Priyono, 2015). Metode overlay tefokus kepada penggabungan variabel pemicu longsoran dengan pendekatan keruangan dan menggunakan data spasial. Namun dalam pengambilan keputusan metode ini merupakan yang paling sederhana terhadap permasalahan intens dan skala yang luas (Srinivas et al., 2018). Selain itu, Metode ini mengedepankan teknologi SIG dalam pengolahan data dan analisisnya.

\section{KESIMPULAN}

Berdasarkan hasil temuan pada penelitian ini, perencanaan kawasan permukiman di Kecamatan Cisarua yang di evaluasi dengan RTRW Kabupaten Bogor 2016 - 2036 terhadap kerawanan bencana tanah longsor, dirasa sudah mengedepankan analisis terhadap kebencanaan. Kemajuan ini merupakan salah satu tindakan preventif untuk membangun resiliensi akan bencana hidometeorologi seperti tanah longsor. Hal ini merupakan bentuk dari mitigasi bencana yang diterapkan pada perencanaan pengembangan wilayah dengan tujuan meminimalisir kemungkinan risiko kerugian mulai dari korban jiwa, hancurnya tempat tinggal dan kehilangan harta benda. Kerawanan tertinggi terdapat pada kemiringan lereng yang curam mengarah ke Puncak Gunung Pangrango dan dalam segi pola ruang masih didominasi oleh hutan. Sedangkan kawasan pemukiman didominasi di kelerengan datar hingga landai. Selanjutnya, pengembangan wilayah yang terjadi kedepannya harus selalu di evaluasi dengan rencana pola ruang dengan konsisten dan regulasi yang kuat. Pengembangan wilayah di masa depan harus mengikuti kaidah dan ketentuan yang telah dirumuskan dalam tahap perencanaan. Hal ini agar terwujudnya tujuan utama dari penyusunan kebijakan spasial tersebut.

\section{DAFTAR PUSTAKA}

Badan Pusat Statistik Kabupaten Bogor. (2019). Kecamatan Cisarua Dalam Angka. In Badan Pusat Statistik Kabupaten Bogor.

BNPB. (2013). Indeks Risiko Bencana. In Bnpb. http://inarisk.bnpb.go.id/irbi.

Dewi, T. S., Kusumayudha, S. B., \& Purwanto, H. S. (2017). Zonasi Rawan Bencana Tanah Longsor Dengan Metode Analsis GIS: Studi 
Kasus Daerah Semono dan Sekitarnya Kecamatan Bagelen, Kabupaten Purworejo, Jawa Tengah. Jurnal Mineral, Energi Dan Lingkungan, $\quad 1(1), \quad 50$. https://doi.org/10.31315/jmel.v1i1.17 73.

Fahmi, F., Sitorus, S. R. ., \& Fauzi, A. (2016). Evaluasi Pemanfaatan Penggunaan Lahan Berbasis Rencana Pola Ruang Kota Baubau, Provinsi Sulawesi Tenggara. Tataloka, $18(1), \quad 27$. https://doi.org/10.14710/tataloka.18. 1.29-46.

Hardianto, A., Winardi, D., Rusdiana, D. D., Putri, A. C. E., Ananda, F., Devitasari, Djarwoatmodjo, F. S., Yustika, F., \& Gustav, F. (2020). Pemanfaatan Informasi Spasial Berbasis SIG untuk Pemetaan Tingkat Kerawanan Longsor di Kabupaten Bandung Barat, Jawa Barat. Jurnal Geosains Dan Remote Sensing, 1(1), 23-31. https://doi.org/10.23960/jgrs.2020.v1 i1.16.

Hasnawir, H. (2012). Intensitas Curah Hujan Memicu Tanah Longsor Dangkal Di Sulawesi Selatan. Jurnal Penelitian Kehutanan Wallacea, l(1),

https://doi.org/10.18330/jwallacea.20 12.vol1iss1pp62-73.

Kahal, A. Y., Abdelrahman, K., Alfaifi, H. J., \& Yahya, M. M. A. (2021). Landslide hazard assessment of the Neom promising city, northwestern Saudi Arabia: An integrated approach. Journal of King Saud University - Science, 33(2), 101279. https://doi.org/10.1016/j.jksus.2020. 101279.

Kusrini, K., Suharyadi, S., \& Hardoyo, S. R. (2016). Perubahan Penggunaan Lahan dan Faktor yang Mempengaruhinya di Kecamatan Gunungpati Kota Semarang.
Perubahan Penggunaan Lahan Dan Faktor Yang Mempengaruhinya Di Kecamatan Gunungpati Kota Semarang, 25(1), 25-40. https://doi.org/10.22146/mgi.13358.

Mandal, B., \& Mandal, S. (2018). Analytical hierarchy process (AHP) based landslide susceptibility mapping of Lish river basin of eastern Darjeeling Himalaya, India. Advances in Space Research, 62(11), 3114-3132.

https://doi.org/10.1016/j.asr.2018.08. 008.

Omukuti, J., Megaw, A., Barlow, M., Altink, H., \& White, P. (2021). The value of secondary use of data generated by non-governmental organisations for disaster risk management research: Evidence from the Caribbean. International Journal of Disaster Risk Reduction, 56(January), 102114. https://doi.org/10.1016/j.ijdrr.2021.1 02114.

Pangaribuan, J., Sabri, L. M., \& Amarrohman, F. J. (2019). Analisis Daerah Rawan Bencana Tanah Longsor Di Kabupaten Magelang Menggunakan Sistem Informasi Geografis Dengan Metode Standar Nasional Indonesia Dan Analythical Hierarchy Process. Jurnal Geodesi Undip, 8(1), 288-297.

Permadi, M. G., Tjahjono, B., \& Baskoro, D. P. T. (2018). Identifikasi Daerah Risiko Bencana Longsor Di Kota Bogor. Jurnal Ilmu Tanah Dan Lingkungan, 20(2), 86-94. https://doi.org/10.29244/jitl.20.2.8694.

Priyono. (2015). Hubungan klasifikasi longsor, klasifikasi tanah rawan longsor dan klasifikasi tanah pertanian rawan longsor. Gema, 27(49), 1602-1617.

Rachmawati, T., Muta'ali, L., \& Santosa, L. W. (2013). Kajian Daya Dukung 
Bioekologikawasan Puncak Kabupaten Bogor. Majalah Geografi Indonesia, 27(2), 180-197. https://doi.org/10.22146/mgi.13430

Rahman, D. A. (2011). Di Pusat Studi Satwa Primata IPB Dan Taman Nasional Gunung Gede Pangrango: Penyiapan Pelepasliaran Dede Aulia Rahman.

Sarya, G., Andriawan, A. H., Ridho, A., \& Seputro, H. (2014). Intensitas Curah Hujan Memicu Tanah Longsor Dangkal di Desa Wonodadi Kulon. Jurnal Pengabdian LPPM UNTAG Surabaya, 1(1), 65-71.

Sihotang, D. M. (2016). Metode Skoring dan Metode Fuzzy dalam Penentuan Zona Resiko Malaria di Pulau Flores. Jurnal Nasional Teknik Elektro Dan Teknologi Informasi (JNTETI), 5(4), 302-308. https://doi.org/10.22146/jnteti.v5i4.2 78

Srinivas, R., Singh, A. P., Dhadse, K., Garg, C., \& Deshmukh, A. (2018). Sustainable management of a river basin by integrating an improved fuzzy based hybridized SWOT model and geo-statistical weighted thematic overlay analysis. Journal of Hydrology, 563(May), 92-105. https://doi.org/10.1016/j.jhydrol.201 8.05.059

Sulistio, S., Rondonuwu, D. M., \& Poli, H. (2020). ISSN 2442-3262 Jurnal Spasial Vol 7 . No . 1, 2020. 7(1), 164-175.

Susanti, P., Miardini, A., \& Harjadi, B. (2017). Jurnal Penelitian Pengelolaan Daerah Aliran Sungai. Analisis Kerentanan Tanah Longsor Sebagai Dasar Mitigasi Di Kabupaten Banjarnegara, 1(1), 49-59.

Trimarwanti, T. K. E. (2014). Evaluasi Perubahan Penggunaan Lahan Kecamatan di Daerah Aliran Sungai Cisadane Kabupaten Bogor. Jurnal Pembangunan Wilayah \& Kota,
10(1),

43. https://doi.org/10.14710/pwk.v10i1.7 632

Yassar, M. F., Nurul, M., Nadhifah, N., Sekarsari, N. F., Dewi, R., Buana, R., Fernandez, S. N., \& Rahmadhita, K. A. (2020). Penerapan Weighted Overlay Pada Pemetaan Tingkat Probabilitas Zona Rawan Longsor di Kabupaten Sumedang, Jawa Barat. Jurnal Geosains Dan Remote Sensing, 1(1), 1-10. https://doi.org/10.23960/jgrs.2020.v1 i1.13. 